\title{
CARACTERÍSTICAS BIOLÓGICAS DO SOLO INDICADORAS DE QUALIDADE APÓS DOIS ANOS DE APLICAÇÃO DE BIOSSÓLIDO INDUSTRIAL E CULTIVO DE MILHO(1)
}

\author{
Isabel Cristina de Barros Trannin ${ }^{(2)}$, José Oswaldo Siqueira ${ }^{(3)} \&$ \\ Fátima Maria de Souza Moreira ${ }^{(3)}$
}

\begin{abstract}
RESUMO
A utilização agrícola de biossólidos tem sido muito incentivada, mas, como esses resíduos apresentam composição química variada, o valor agronômico e os efeitos sobre características indicadoras de qualidade do solo precisam ser avaliados caso a caso, a fim de estabelecer normas de segurança para uso desses materiais. Neste trabalho foram avaliadas características biológicas, após a aplicação, por dois anos consecutivos, de doses crescentes $\left(0,6,12,18\right.$ e 24 t ha $^{-1}$ base seca) de um biossólido gerado por uma indústria de fibras e resinas PET e da adubação mineral completa no cultivo de milho, em um Cambissolo distrófico, comparados aos de uma área adjacente, sob Brachiaria sp. e sem cultivo nos últimos 10 anos, usada como referência. Os valores de $\mathrm{C}$ e $\mathrm{N}$ da biomassa microbiana, a respiração basal e as atividades das enzimas urease e $\beta$-glicosidase e da hidrólise do diacetato de fluoresceína (FDA) aumentaram, enquanto a atividade da fosfatase ácida diminuiu com a elevação das doses de biossólido, porém estas não tiveram efeito sobre o quociente metabólico $\left(q \mathrm{CO}_{2}\right)$. A diminuição da atividade da fosfatase se deveu ao aumento da disponibilidade de $\mathbf{P}$ no solo, não caracterizando efeito adverso da aplicação do biossólido. Com aplicação de $12 \mathrm{t} \mathrm{ha}^{-1}$ de biossólido (recomendação agronômica), a respiração e a hidrólise da FDA foram maiores e a atividade da fosfatase foi menor que a obtida no solo com adubação mineral, mas as demais características avaliadas não diferiram entre estes tratamentos. A colonização micorrízica de Brachiaria sp. não diferiu entre plantas de crescimento espontâneo nas parcelas anteriormente cultivadas com milho e aquelas da área adjacente. Apesar do menor número de esporos, verificou-se enriquecimento de espécies de fungos micorrízicos arbusculares (FMAs) nas parcelas cultivadas. $O$
\end{abstract}

\footnotetext{
(1) Parte da Tese de Doutorado do primeiro autor apresentada ao Departamento de Ciência do Solo, Universidade Federal de Lavras - UFLA. Trabalho parcialmente financiado pelo convênio FAEPE/Rhodia-ster S.A/DCS-UFLA. Recebido para publicação em agosto de 2006 e aprovado em junho de 2007.

${ }^{(2)}$ Professora da Universidade Estadual Paulista Júlio de Mesquita Filho - UNESP/Faculdade de Engenharia de Guaratinguetá. Av. Dr. Ariberto Pereira da Cunha 333, Pedregulho CEP 12516-410. E-mail: isatrannin@uol.com.br; isatrannin@feg.unesp.br

${ }^{(3)}$ Professores do Departamento de Ciência do Solo da Universidade Federal de Lavras - UFLA. Campus Universitário, Caixa Postal 3037, CEP 37200-000 Lavras (MG). E-mails: siqueira@ufla.br; fmoreira@ufla.br
} 
carbono orgânico (Corg) e a biomassa microbiana apresentaram alta correlação com os demais parâmetros avaliados, indicando que as alterações na quantidade e qualidade da matéria orgânica, promovidas pela aplicação do biossólido, refletiram na dinâmica da microbiota e influenciaram positivamente os parâmetros biológicos de qualidade do solo.

Termos de indexação: lodo de esgoto, biomassa microbiana, respiração, quociente metabólico $\left(q \mathrm{CO}_{2}\right)$, enzimas do solo, diacetato de fluoresceína (FDA), $\beta$-glicosidase, urease, fosfatase, fungos micorrízicos arbusculares (FMAs).

\title{
SUMMARY: BIOLOGICAL CHARACTERISTICS INDICATORS OF SOIL QUALITY AFTER TWO YEARS OF APPLICATION OF AN INDUSTRIAL BIOSOLID AND CORN CULTIVATION
}

\begin{abstract}
The agricultural use of biosolids has been stimulated, however, as the chemical composition of these residues is varied, the agronomic value and effects on soil quality characteristics need to be individually assessed in order to establish safety norms for their application. The present work evaluated biological characteristics after the application for two consecutive years of increasing doses $\left(0,6,12,18\right.$ and $24 t h^{-1}$ dry matter) of biosolid generated by a PET fiber and resin industry. There was also a complete mineral fertilizer treatment in corn cultivation in a Cambisol, compared to an adjacent area under Brachiaria sp. without cultivation for the last ten years. The microbial biomass $C$ and $N$, basal respiration and urease, $\beta$-glucosidase and fluorescein diacetate hydrolysis activities were increased, while the acid phosphatase activity was reduced with the increase of biosolid rates. The different biosolid doses had no effect on the microbial metabolic quotient (qCO $\mathrm{CO}_{2}$ ). The decrease in phosphatase activity was related to the increase in phosphorus availability in soil rather than representing an adverse effect to biosolid application. With the application of $12 \mathrm{Mg} \mathrm{ha}^{-1}$ biosolid (agronomic recommendation), the basal respiration and fluorescein diacetate hydrolysis were higher and the phosphatase activity lower than in the soil that received mineral fertilizer, while the other parameters were not affected by these treatments. The mycorrhizal colonization of Brachiaria sp. did not differ among spontaneously growing plants in plots previously cultivated with corn and those of adjacent area. In spite of the lower spore number, an enrichment in the arbuscular mycorrhizal fungi species was observed in the cultivated plots. Organic carbon and microbial biomass were highly correlated with the other characteristics. This indicates that the changes in the amount and quality of soil organic matter, as a result of biosolid application, altered microbial dynamics and influenced the biological parameters of soil quality positively.
\end{abstract}

Index terms: sewage sludge, microbial biomass, soil respiration, microbial metabolic quotient $\left(q \mathrm{CO}_{2}\right)$, microbial activity, soil enzymes, fluorescein diacetate (FDA), $\beta$-glucosidase, urease, phosphatase, arbuscular mycorrhizal fungi.

\section{INTRODUÇÃO}

A utilização de biossólidos na agricultura é relativamente recente em nosso país, e as informações sobre as eventuais alterações na qualidade dos solos brasileiros pela adoção dessa prática ainda são escassas e restritas a biossólidos de origem domiciliar. Além disso, há grande demanda por estudos com biossólidos de origem industrial, que têm sido gerados em volumes cada vez maiores por empresas dos mais variados setores. Como apresentam composição química muito variável em função do tipo de efluente tratado, do processo de tratamento empregado e da qualidade do material gerado, esses resíduos precisam ser avaliados caso a caso, quanto ao valor agronômico e aos possíveis efeitos sobre a qualidade do solo, para que sejam aplicados de forma eficiente e segura em sistemas agrícolas (Bettiol \& Camargo, 2000).

Como a microbiota do solo é a principal responsável pela decomposição dos compostos orgânicos, pela ciclagem de nutrientes e pelo fluxo de energia do solo, a biomassa microbiana e sua atividade têm sido apontadas como as características mais sensíveis às alterações na qualidade do solo, causadas por mudanças de uso e práticas de manejo, como as promovidas pela aplicação de resíduos orgânicos (Debosz et al., 2002). De fato, a aplicação de biossólidos pode afetar diretamente a biomassa microbiana, já 
que esta se relaciona ao teor e à qualidade da matéria orgânica, representando de 2 a 5 dag kg-1 do C orgânico (Jenkinson \& Ladd, 1981) e de 1 a 5 dag $\mathrm{kg}^{-1}$ do N total do solo (Smith \& Paul, 1990). As relações Cmicrobiano/Corgânico e Nmicrobiano/Ntotal expressam índices de qualidade nutricional da matéria orgânica e as relações Cmicrobiano/Nmicrobiano e Corgânico/Ntotal, a eficiência da biomassa em imobilizar C ou N, e são adequadas para avaliar os efeitos da aplicação de resíduos orgânicos sobre a biota do solo (Gama-Rodrigues \& De-Polli, 2000).

A atividade microbiana medida pela respiração, o quociente metabólico $\left(q \mathrm{CO}_{2}\right)$ e as atividades enzimáticas também têm sido empregados para avaliar os efeitos da aplicação de biossólidos na biologia do solo. García-Gil et al. (2000) observaram que a aplicação de $80 \mathrm{t} \mathrm{ha}^{-1}$ de lodo compostado em solo arenoso durante nove anos aumentou em $46 \%$ o C da biomassa e em mais de $100 \%$ a atividade da $\beta$ glicosidase, porém reduziu em $62 \%$ a atividade da fosfatase ácida, devido ao aumento de P solúvel, e em $28 \%$ a atividade da urease, em razão dos altos teores de metais pesados e de $\mathrm{N}-\mathrm{NH}_{4}{ }^{+}$daquele resíduo. Gagnon et al. (2000) verificaram aumento linear na atividade da fosfatase ácida em resposta às doses de 8 a $65 \mathrm{t} \mathrm{ha}^{-1}$ do biossólido gerado por indústria de celulose aplicadas a um solo orgânico utilizado para horticultura, mesmo após três anos da aplicação. Chantigny et al. (2000) constataram que a aplicação de $50 \mathrm{t} \mathrm{ha}^{-1}$ de biossólido, também gerado por indústria de celulose, a um solo argiloso aumentou em $100 \%$ o C da biomassa e em $40 \%$ a hidrólise do diacetato de fluoresceína (FDA), que manteve atividade superior à do controle três anos após a aplicação. Por sua vez, Debosz et al. (2002) verificaram que os efeitos da aplicação de 4,2 $\mathrm{t} \mathrm{ha}^{-1}$ de biossólido municipal sobre $\mathrm{C}$ e $\mathrm{N}$ da biomassa, respiração, $q \mathrm{CO}_{2}$, hidrólise da FDA e atividade da $\beta$-glicosidase foram transientes. Esses estudos mostram que a utilização agrícola de biossólidos pode ter efeitos diversos sobre importantes características biológicas do solo, como a biomassa microbiana e a atividade enzimática, que respondem às mudanças de uso e práticas de manejo em curto espaço de tempo e fornecem informação segura e consistente sobre a qualidade do solo (García-Gil et al., 2000). A aplicação de biossólidos pode melhorar a qualidade do solo, devido ao incremento de matéria orgânica e à ativação de processos biológicos e bioquímicos; contudo, a presença de metais pesados e de outros potenciais poluentes pode inibir processos bioquímicos essenciais à mineralização da fração orgânica, limitando o uso agrícola desses resíduos (García-Gil et al., 2000).

Possíveis impactos da aplicação de biossólidos no solo podem ocorrer também sobre a comunidade de fungos micorrízicos arbusculares (FMAs), que desempenham importante papel no crescimento das plantas, já que há evidências de efeitos adversos da presença de metais pesados ou outros compostos orgânicos tóxicos no biossólido sobre essa simbiose
(Koomen et al., 1990). Os efeitos dos metais pesados dependem da concentração e da disponibilidade desses elementos no biossólido e, por isso, nem sempre a aplicação desses resíduos inibe a colonização micorrízica, como foi verificado em plantas de milho (Weissenhorn et al., 1995) e para mudas de maracujazeiro (Silva Neto, 2001). Estudos do comportamento de FMAs em solos tratados com biossólidos sob condições tropicais são escassos e tornam-se importantes para avaliação desses resíduos como insumo agrícola.

Em trabalho já publicado, foi demonstrado que a aplicação, por dois anos consecutivos, de doses crescentes $\left(0,6,12,18\right.$ e $24 \mathrm{t} \mathrm{ha}^{-1}$ base seca) do biossólido gerado por uma indústria de fibras e resinas PET em um Cambissolo distrófico não resultou em aumento nos teores de metais pesados no solo e nos tecidos foliares e melhorou a fertilidade do solo, a nutrição e a produtividade do milho (Trannin et al., 2005). Este estudo relata os efeitos de dois anos de aplicação de doses crescentes do biossólido e da adubação mineral completa no cultivo de milho, sobre características biológicas indicadoras de qualidade do solo, por comparação aos de área adjacente, com Brachiaria sp., usada como área referência.

\section{MATERIAL E MÉTODOS}

Nos anos agrícolas 1999/2000 e 2000/2001, foi realizado um experimento de campo em área de Cambissolo distrófico sob vegetação de Brachiaria sp., próxima à Rhodia-ster S.A., em Poços de Caldas (MG), que comprovou a viabilidade econômica do uso agrícola do biossólido gerado por essa empresa para cultura do milho (Trannin et al., 2005). Para implantação deste experimento com a cultura do milho, a área foi arada, gradeada e recebeu $2,5 \mathrm{t} \mathrm{ha}^{-1}$ de calcário dolomítico. Aos 30 dias após a calagem, amostras da camada de 0 a $20 \mathrm{~cm}$ do perfil do solo foram analisadas química e fisicamente, apresentando: $\mathrm{pH}$ em água $(1: 2,5)=6,3$; $\mathrm{P}=2 \mathrm{mg} \mathrm{dm}{ }^{-3} ; \mathrm{K}=117 \mathrm{mg} \mathrm{dm}^{-3} ; \mathrm{SO}_{4}=31 \mathrm{mg} \mathrm{dm}^{-3}$; $\mathrm{Ca}^{2+}=4,2 \mathrm{cmol}_{\mathrm{c}} \mathrm{dm}^{-3} ; \mathrm{Mg}^{2+}=1,7 \mathrm{cmol}_{\mathrm{c}} \mathrm{dm}^{-3} ; \mathrm{Cu}=$ $0,7 \mathrm{mg} \mathrm{dm}^{-3} ; \mathrm{Mn}=6 \mathrm{mg} \mathrm{dm}^{-3} ; \mathrm{Zn}=0,4 \mathrm{mg} \mathrm{dm}^{-3} ; \mathrm{Fe}=$ $23 \mathrm{mg} \mathrm{dm}^{-3} ; \mathrm{Na}=7,4 \mathrm{mg} \mathrm{dm}^{-3} ; \mathrm{Pb}=1,3 \mathrm{mg} \mathrm{dm}^{-3}$; $\mathrm{Cd}=0,1 \mathrm{mg} \mathrm{dm}-3 ; \mathrm{Al}=0 \mathrm{cmol}_{\mathrm{c}} \mathrm{dm}^{-3} ; \mathrm{H}+\mathrm{Al}=$ $3,6 \mathrm{cmol}_{\mathrm{c}} \mathrm{dm}^{-3} ; \mathrm{V}=63 \%$; e CO $=25 \mathrm{~g} \mathrm{~kg}^{-1}$. A composição granulométrica foi de 80,270 e $650 \mathrm{~g} \mathrm{~kg}^{-1}$ de areia, silte e argila, respectivamente, remetendo o solo à classe textural argilosa.

O biossólido empregado foi obtido do leito de secagem da Estação de Tratamento de Efluentes (ETE) industriais gerados na produção de fibras e resinas de polietileno tereftalato (PET) pela Rhodia-ster S.A. e classificado como "Classe II - resíduo não inerte", de acordo com métodos do Standard Methods of Water and Wastewater-19a edição/SW846 do EPA. Os dois lotes utilizados nas duas aplicações foram analisados, conforme métodos descritos por Eaton et al. (1995), e 
suas características químicas estão apresentadas no quadro 1. Verifica-se que os teores de $\mathrm{Zn}, \mathrm{Cu}, \mathrm{As}, \mathrm{Cd}$, $\mathrm{Pb}, \mathrm{Hg}$, Ni e Se no biossólido são muito inferiores aos limites estabelecidos pela Cetesb (1999).

O delineamento experimental empregado foi o de blocos ao acaso, com seis tratamentos distribuídos em quatro blocos, totalizando 24 parcelas de $40 \mathrm{~m}^{2}$ plantadas com milho. Os tratamentos aplicados foram: controle - sem adubação; adubação mineral completa - $400 \mathrm{~kg} \mathrm{ha}^{-1}$ da fórmula 4-30-16 + Zn no sulco de semeadura e cobertura aos 30 dias com $80 \mathrm{~kg} \mathrm{ha}^{-1} \mathrm{de}$ $\mathrm{K}_{2} \mathrm{O}$, como $\mathrm{KCl}$, e aos 30 e 60 dias com 80 e $55 \mathrm{~kg} \mathrm{ha}^{-1}$ de $\mathrm{N}$ na forma de uréia; e biossólido nas doses de 6 ,
12, 18 e 24 t ha ${ }^{-1}$. As doses de biossólido em base seca foram determinadas em função do teor de N-total, considerando a disponibilidade anual de $20 \%$ (Cetesb, 1999), e corresponderam a 0, 0,5, 1,0 e 2,0 vezes a quantidade de $\mathrm{N}$ aplicada no tratamento com adubação mineral recomendada para cultura do milho. Os tratamentos foram repetidos no segundo cultivo de milho, mas aqueles com biossólido, além da complementação com $\mathrm{K}_{2} \mathrm{O}$, receberam suplementação com $30 \%\left(36 \mathrm{~kg} \mathrm{ha}^{-1}\right)$ de $\mathrm{P}_{2} \mathrm{O}_{5}$ do total adicionado no tratamento com adubação mineral, para corrigir deficiências nutricionais observadas no primeiro ano (Trannin et al., 2005).

Quadro 1. Caracterização química dos lotes de biossólido em base seca, coletados na ETE da Rhodia-ster S.A., em Poços de Caldas, MG, aplicados na cultura do milho nos anos agrícolas 1999/2000 e 2000/2001 valores típicos e limites de metais pesados para lodo de esgoto

\begin{tabular}{|c|c|c|c|c|}
\hline Característica química ${ }^{(1)}$ & $1999 / 2000$ & $2000 / 2001$ & Valor típico $^{(2)}$ & Limite máximo ${ }^{(3)}$ \\
\hline $\mathrm{pH}\left(\mathrm{CaCl}_{2} 0,01 \mathrm{~mol} \mathrm{~L}^{-1}\right)$ & 7,3 & 6,6 & Bioestabilizado $=7,5$ & \\
\hline Umidade total (dag kg ${ }^{-1}$ ) & 80 & 82 & $>80$ & \\
\hline Inertes $\left(\mathrm{g} \mathrm{kg}^{-1}\right)$ & 0 & 0 & 0 & \\
\hline Matéria orgânica (MO) total ( $\left.\mathrm{g} \mathrm{kg}^{-1}\right)$ & 780 & 755 & $>50 \%$ do peso & \\
\hline MO compostável $\left(\mathrm{g} \mathrm{kg}^{-1}\right)$ & 560 & 638 & $80 \%$ da MO total & \\
\hline MO resistente à compostagem $\left(\mathrm{g} \mathrm{kg}^{-1}\right)$ & 220 & 116 & $15-20 \%$ da MO total & \\
\hline Carbono total $\left(\mathrm{g} \mathrm{kg}^{-1}\right)$ & 433 & 419 & 170 & \\
\hline Carbono orgânico $\left(\mathrm{g} \mathrm{kg}^{-1}\right)$ & 311 & 355 & - & \\
\hline Resíduo mineral ( $\mathrm{g} \mathrm{kg}^{-1}$ ) & 220 & 245 & - & \\
\hline Resíduo min. insolúvel ( $\mathrm{g} \mathrm{kg}^{-1}$ ) & 39 & 75 & - & \\
\hline Resíduo mineral solúvel ( $\left.\mathrm{g} \mathrm{kg}^{-1}\right)$ & 181 & 170 & - & \\
\hline Nitrogênio total $\left(\mathrm{g} \mathrm{kg}^{-1}\right)$ & 64 & 54 & 16 (variável) & \\
\hline Fósforo $\left(\mathrm{P}_{2} \mathrm{O}_{5}\right)\left(\mathrm{g} \mathrm{kg}^{-1}\right)$ & 47 & 76 & $8(>15=$ alto $)$ & \\
\hline Potássio $\left(\mathrm{K}_{2} \mathrm{O}\right)\left(\mathrm{g} \mathrm{kg}^{-1}\right)$ & 2 & 5 & $2(<5=$ baixo $)$ & \\
\hline Cálcio $\left(\mathrm{g} \mathrm{kg}^{-1}\right)$ & 5 & 10 & $16(<15=$ baixo $)$ & \\
\hline Magnésio $\left(\mathrm{g} \mathrm{kg}^{-1}\right)$ & 2 & 3 & $6(<6=$ baixo $)$ & \\
\hline Enxofre $\left(\mathrm{g} \mathrm{kg}^{-1}\right)$ & 2 & 2 & $2(<2=$ baixo $)$ & \\
\hline $\mathrm{C} / \mathrm{N}$ & 7 & 8 & 11 (libera $\mathrm{NH}_{4}^{+}$) & \\
\hline Ferro $\left(\mathrm{mg} \mathrm{kg}^{-1}\right)$ & 8.229 & 14.943 & - & \\
\hline Manganês (mg kg ${ }^{-1}$ ) & 137 & 360 & - & \\
\hline Zinco $\left(\mathrm{mg} \mathrm{kg}^{-1}\right)$ & 1.217 & 1.047 & 900 & 7.500 \\
\hline Cobre $\left(\mathrm{mg} \mathrm{kg}^{-1}\right)$ & 147 & 180 & 435 & 4.300 \\
\hline $\operatorname{Arsênio}^{(4)}\left(\mathrm{mg} \mathrm{kg}^{-1}\right)$ & $<2$ & $<2$ & - & 75 \\
\hline Cádmio $^{(4)}\left(\mathrm{mg} \mathrm{kg}^{-1}\right)$ & $<0,5$ & $<0,5$ & 11 & 85 \\
\hline $\mathrm{Chumbo}^{(4)}\left(\mathrm{mg} \mathrm{kg}^{-1}\right)$ & 12 & 16 & 360 & 840 \\
\hline Mercúrio(4) $\left(\mathrm{mg} \mathrm{kg}^{-1}\right)$ & $<1,25$ & $<1,25$ & - & 57 \\
\hline $\operatorname{Níquel}^{(4)}\left(\mathrm{mg} \mathrm{kg}^{-1}\right)$ & 35,7 & 32,5 & 362 & 420 \\
\hline Selênio(4) $\left(\mathrm{mg} \mathrm{kg}^{-1}\right)$ & $<3$ & $<3$ & - & 100 \\
\hline Sódio $\left(\mathrm{mg} \mathrm{kg}^{-1}\right)$ & 3.287 & 3.633 & - & (5) \\
\hline
\end{tabular}

(1) Conforme Eaton et al. (1985). ${ }^{(2)}$ Conforme Raij et al. (1997) e Kiehl (1985). (3) Concentração-limite de metal em lodo de esgoto (Cetesb, 1999). ${ }^{(4)}$ Determinado por Ecolabor Comercial e Análises Ltda. ${ }^{(5)}$ Limite a ser estabelecido pelo Órgão Estadual de Controle Ambiental. 
Após os dois anos consecutivos de cultivo de milho com as diferentes doses de biossólido e adubação mineral completa, avaliaram-se os efeitos desses tratamentos sobre características biológicas indicadoras de qualidade do solo, tendo como referência a área adjacente coberta com Brachiaria sp. e sem cultivo nos últimos 10 anos. Para essas avaliações, dois meses após a última colheita de milho, em julho de 2001, foram retiradas quatro amostras simples da camada de 0-20 cm da área útil de cada parcela experimental, que originaram uma amostra composta de solo por parcela. Na área adjacente, coberta com Brachiaria sp., também foram coletadas quatro amostras compostas em pontos distantes de $15 \mathrm{~m}$ e em cota superior à da área experimental. O solo amostrado foi peneirado, para remoção de resíduos vegetais, e armazenado em geladeira $\left(4^{\circ} \mathrm{C}\right)$ por uma semana, para realização das análises biológicas, descritas a seguir.

$\mathrm{O}$ carbono da biomassa microbiana (Cmic) foi avaliado pelo método da fumigação-extração (Vance et al., 1987), adotando-se o coeficiente de correção de 0,30, proposto por Feigl et al. (1995) para solos tropicais. O nitrogênio da biomassa microbiana (Nmic) também foi avaliado pelo método da fumigaçãoextração, adotando-se o coeficiente de correção de 0,45 , proposto por Brookes et al. (1985). Os quocientes microbianos, ou relações Cmic/Corg e Nmic/Ntotal, foram calculados de acordo com Sparling (1992). As relações C/N entre Corg e Ntotal e entre Cmic e Nmic também foram calculadas.

A respiração basal foi determinada por meio da captura do $\mathrm{CO}_{2}$ liberado do solo por solução de $\mathrm{NaOH}$ $0,05 \mathrm{~mol} \mathrm{~L}^{-1}$, durante $72 \mathrm{~h}$ de incubação em recipiente hermeticamente fechado, mantido no escuro a $28^{\circ} \mathrm{C}$, como descrito em Alef \& Nannipieri (1995). O quociente metabólico $\left(q \mathrm{CO}_{2}\right)$ foi calculado pela razão entre o C- $\mathrm{CO}_{2}$ da respiração basal e o $\mathrm{C}$ da biomassa microbiana (Cmic) das amostras, conforme Anderson \& Domsch (1993).

A atividade da urease foi avaliada pelo método descrito por Tabatabai \& Bremmer (1972), que se baseia na determinação do amônio liberado após incubação do solo com solução de uréia. A atividade da fosfatase ácida foi avaliada seguindo o método de Dick et al. (1996). A atividade da $\beta$-glicosidase foi determinada por espectrofometria do $\rho$-nitrofenol- $\beta$-Dglucosídeo, conforme descrito por Eivazi \& Tabatabai (1988). A hidrólise do diacetato de fluoresceína (FDA) por células microbianas viáveis foi avaliada conforme Diack (1997). As atividades específicas das enzimas nas amostras de solo foram calculadas pela razão entre a atividade total ( $\mu \mathrm{g} \mathrm{g}^{-1} \mathrm{~h}^{-1}$ de produto solo seco) e o Cmic ( $\mu \mathrm{g} \mathrm{g}^{-1}$ de $\mathrm{C}$ no solo seco), sendo expressas em $\mu \mathrm{g} \mathrm{h}^{-1} \mathrm{de}$ produto $\mu \mathrm{g}^{-1} \mathrm{Cmic}$, conforme Waldrop et al. (2000).

A colonização micorrízica foi avaliada em raízes de Brachiaria sp., comparando-se plantas coletadas na área adjacente com plantas de crescimento espontâneo nas parcelas cultivadas, após a última colheita de milho. Amostras de $1 \mathrm{~g}$ de raízes finas foram separadas do solo, lavadas em água e clarificadas em solução aquosa de KOH $\left(100 \mathrm{~g} \mathrm{~L}^{-1}\right)$ e coloridas com azul de tripano (Philips \& Hayman, 1970). A colonização foi estimada pelo método da placa quadriculada de Giovanetti \& Mosse (1980), e a densidade de esporos, determinada conforme Gerdemann \& Nicolson (1963). Após lavagem dos esporos em água, estes foram distribuídos em placa de Petri canaletada e contados com auxílio de microscópio estereoscópico (40x).

Os dados foram submetidos à análise de variância e, quando ocorreram diferenças significativas, aplicaram-se testes de médias e análises de regressão, utilizando-se o programa estatístico SISVAR (Ferreira, 1999/2003). Também foi feita análise de correlação entre as características biológicas avaliadas.

\section{RESULTADOS E DISCUSSÃO}

Os resultados apresentados no quadro 2 mostram que, mesmo após dois anos da aplicação dos tratamentos no cultivo do milho, estes tiveram efeito significativo sobre algumas características biológicas do solo. Com a aplicação de doses superiores a $12 \mathrm{t} \mathrm{ha}^{-1}$ de biossólido, os valores de $\mathrm{C}$ e $\mathrm{N}$ da biomassa microbiana (Cmic e Nmic) superaram os obtidos no tratamento com adubação mineral e os da área adjacente, sendo os menores valores observados no controle. A respiração basal $\left(\mathrm{C}-\mathrm{CO}_{2}\right)$ foi estimulada por todos os tratamentos quando comparada à área adjacente, mas-manteve-se mais elevada com a aplicação do biossólido. Embora o uso de biossólido tenha promovido aumento da atividade microbiana do solo, a respiração específica da biomassa ou quociente metabólico $\left(q \mathrm{CO}_{2}\right)$ não diferiu significativamente entre este e os demais tratamentos.

O Cmic, o Nmic e a respiração basal aumentaram linearmente com a elevação das doses de biossólido, porém estas não tiveram efeito sobre o $q_{\mathrm{CO}_{2}}$ (Quadro 2). A aplicação da dose máxima aumentou em três vezes o Cmic, que atingiu $1.081 \mu \mathrm{g} \mathrm{g}^{-1} \mathrm{de} C$ no solo seco e dobrou os valores de Nmic e da respiração, que foram, respectivamente, de $44 \mu \mathrm{g} \mathrm{g}^{-1}$ de $\mathrm{N}$ no solo seco e $48 \mu \mathrm{g} \mathrm{g}^{-1} \mathrm{~h}^{-1}$ de C-CO $\mathrm{CO}_{2}$ no solo seco. Esses aumentos refletem o estímulo à microbiota do solo causado pelo fornecimento de substratos orgânicos e nutrientes e os baixos teores de metais pesados deste resíduo. Segundo Brookes (1995), o $q \mathrm{CO}_{2}$ pode ser interpretado como "eficiência microbiana", já que se trata da avaliação da energia necessária para manutenção da atividade metabólica em relação à energia utilizada para síntese de biomassa, ocorrendo em muitos casos maior consumo de energia em estados de estresse. Portanto, os resultados obtidos para o $q_{\mathrm{CO}}$ indicaram que a aplicação deste biossólido não causou efeito adverso à comunidade microbiana e que esta manteve sua eficiência na ciclagem da fração orgânica do biossólido. Resultados análogos foram verificados por Banerjee et al. (1997) em solo tratado 
Quadro 2. Características biológicas do solo após dois anos consecutivos da aplicação de doses crescentes de biossólido industrial e de adubação mineral no cultivo de milho e do solo da área adjacente, coberta com Brachiaria sp., sem cultivo nos últimos $10 \operatorname{anos}^{(1)}$

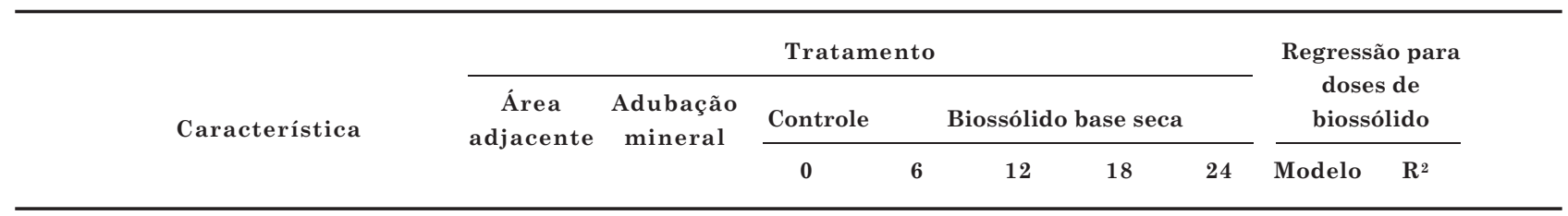

\section{Cmic}

$\left(\mu \mathrm{g} \mathrm{g}^{-1}\right.$ de C no solo seco)

Nmic

( $\mu \mathrm{g} \mathrm{g}^{-1}$ de $\mathrm{N}$ no solo seco)

Respiração

( $\mu \mathrm{g} \mathrm{g}^{-1} \mathrm{~h}^{-1}$ de $\mathrm{C}-\mathrm{CO}_{2}$ no solo seco)

$\mathrm{Nmic} / \mathrm{N}$ total (\%)

Cmic/Corg (\%)

Corg/N total

Cmic/Nmic

$q \mathrm{CO}_{2}$

$\left(\mu \mathrm{g} \mathrm{h}^{-1} \mathrm{C}-\mathrm{CO}_{2} \mu \mathrm{g}^{-1} \mathrm{Cmic}\right)$

\section{$\beta$-glicosidase}

( $\mu \mathrm{g} \mathrm{g}^{-1} \mathrm{~h}^{-1}$ de PNG no solo seco)

Urease $\left(\mu \mathrm{g} \mathrm{g}^{-1} \mathrm{~h}^{-1}\right.$ de N-NH${ }_{4}$ no

solo seco)

Fosfatase $\left(\mu \mathrm{g} \mathrm{g}^{-1} \mathrm{~h}^{-1}\right.$ de PNF no solo seco)

FDA ( $\mu \mathrm{g} \mathrm{g}^{-1} \mathrm{~h}^{-1}$ de fluoresceína no solo seco)

\section{$\beta$-glicosidase}

$\left(\mu \mathrm{g} \mathrm{h}^{-1}\right.$ PNG $\left.\mu \mathrm{g}^{-1} \mathrm{Cmic}\right)$

Urease

$\left(\mu \mathrm{g} \mathrm{h}^{-1} \mathrm{~N}-\mathrm{NH}_{4} \mu \mathrm{g}^{-1} \mathrm{Cmic}\right)$

Fosfatase

( $\left.\mu \mathrm{g} \mathrm{h}^{-1} \mathrm{PNF} \mu \mathrm{g}^{-1} \mathrm{Cmic}\right)$

FDA

( $\mu \mathrm{g} \mathrm{h}^{-1}$ fluoresceína $\left.\mu \mathrm{g}^{-1} \mathrm{Cmic}\right)$

Colonização da

Brachiaria sp. (\%)

Número de esporos

$50 \mathrm{~g}^{-1}$ de solo

Biomassa, respiração, quocientes microbianos e metabólico

$\begin{array}{ccccccccc}439 \mathrm{bc} & 576 \mathrm{bc} & 355 \mathrm{c} & 715 \mathrm{abc} & 782 \mathrm{ab} & 993 \mathrm{a} & 1.081 \mathrm{a} & \mathrm{L} & 0,93^{* *} \\ 26 \mathrm{~d} & 29 \mathrm{~cd} & 19 \mathrm{e} & 28 \mathrm{~d} & 32 \mathrm{bc} & 36 \mathrm{~b} & 44 \mathrm{a} & \mathrm{L} & 0,97^{* *} \\ & & & & & & & & \\ 25 \mathrm{~g} & 35 \mathrm{e} & 27 \mathrm{f} & 37 \mathrm{~d} & 39 \mathrm{c} & 43 \mathrm{~b} & 48 \mathrm{a} & \mathrm{L} & 0,93^{* *} \\ & & & & & & & & \\ 2,2 \mathrm{a} & 2,0 \mathrm{a} & 1,9 \mathrm{a} & 1,6 \mathrm{a} & 1,7 \mathrm{a} & 1,7 \mathrm{a} & 1,9 \mathrm{a} & \mathrm{ns} & \mathrm{ns} \\ 2,4 \mathrm{a} & 2,7 \mathrm{a} & 2,5 \mathrm{a} & 3,0 \mathrm{a} & 3,0 \mathrm{a} & 2,9 \mathrm{a} & 2,9 \mathrm{a} & \mathrm{ns} & \mathrm{ns} \\ 15 \mathrm{a} & 15 \mathrm{a} & 14 \mathrm{a} & 14 \mathrm{a} & 14 \mathrm{a} & 16 \mathrm{a} & 17 \mathrm{a} & \mathrm{ns} & \mathrm{ns} \\ 17 \mathrm{a} & 20 \mathrm{a} & 19 \mathrm{a} & 26 \mathrm{a} & 25 \mathrm{a} & 27 \mathrm{a} & 25 \mathrm{a} & \mathrm{ns} & \mathrm{ns} \\ 0,06 \mathrm{a} & 0,06 \mathrm{a} & 0,08 \mathrm{a} & 0,05 \mathrm{a} & 0,05 \mathrm{a} & 0,04 \mathrm{a} & 0,04 \mathrm{a} & \mathrm{ns} & \mathrm{ns}\end{array}$

$\begin{array}{rrrrrrrrr}863 \mathrm{ab} & 783 \mathrm{~d} & 776 \mathrm{~d} & 795 \mathrm{~cd} & 816 \mathrm{bcd} & 852 \mathrm{abc} 895 \mathrm{a} & \mathrm{L} & 0,97^{* *} \\ 154 \mathrm{~b} & 384 \mathrm{ab} & 151 \mathrm{~b} & 283 \mathrm{ab} & 290 \mathrm{ab} & 278 \mathrm{ab} & 555 \mathrm{a} & \mathrm{Q} & 0,80^{*} \\ & & & & & & & & \\ 692 \mathrm{a} & 601 \mathrm{bc} & 633 \mathrm{ab} & 517 \mathrm{~cd} & 471 \mathrm{de} & 457 \mathrm{de} & 393 \mathrm{e} & \mathrm{L} & 0,91^{* *} \\ 149 \mathrm{e} & 230 \mathrm{e} & 76 \mathrm{~g} & 313 \mathrm{~d} & 393 \mathrm{c} & 534 \mathrm{~b} & 632 \mathrm{a} & \mathrm{L} & 0,97^{* *}\end{array}$

Atividade enzimática específica

$\begin{array}{cccccccccc}2,0 \mathrm{a} & 1,4 \mathrm{ab} & 2,2 \mathrm{a} & 1,1 \mathrm{ab} & 1,0 \mathrm{ab} & 0,9 \mathrm{ab} & 0,8 \mathrm{~b} & \mathrm{Q} & 0,92^{* *} \\ 0,4 \mathrm{a} & 0,7 \mathrm{a} & 0,4 \mathrm{a} & 0,4 \mathrm{a} & 0,4 \mathrm{a} & 0,3 \mathrm{a} & 0,5 \mathrm{a} & \mathrm{ns} & \mathrm{ns} \\ 1,6 \mathrm{a} & 1,0 \mathrm{ab} & 1,8 \mathrm{a} & 0,7 \mathrm{~b} & 0,6 \mathrm{~b} & 0,5 \mathrm{~b} & 0,4 \mathrm{~b} & \mathrm{Q} & 0,93^{* *} \\ 0,3 \mathrm{~b} & 0,4 \mathrm{ab} & 0,2 \mathrm{~b} & 0,4 \mathrm{ab} & 0,5 \mathrm{a} & 0,5 \mathrm{a} & 0,6 \mathrm{a} & \mathrm{Q} & 0,96^{* *}\end{array}$

Micorriza arbuscular

$\begin{array}{rrrrrrrrr}26 \mathrm{a} & 15 \mathrm{a} & 11 \mathrm{a} & 13 \mathrm{a} & 14 \mathrm{a} & 13 \mathrm{a} & 8,3 \mathrm{a} & \mathrm{ns} & \mathrm{ns} \\ 27 \mathrm{a} & 7 \mathrm{~b} & 22 \mathrm{ab} & 9 \mathrm{~b} & 5 \mathrm{~b} & 11 \mathrm{~b} & 6 \mathrm{~b} & \mathrm{~ns} & \mathrm{~ns}\end{array}$

(1) Médias seguidas da mesma letra não diferem entre si, na horizontal, pelo de teste Tukey (p < 0,05); Cmic: C da biomassa microbiana; Nmic: $\mathrm{N}$ da biomassa microbiana; qCO2: quociente metabólico (C-CO $2 / \mathrm{Cmic}_{\text {) }}$; FDA: hidrólise do diacetato de fluoresceína; Corg: carbono orgânico; Ntotal: $\mathrm{N}$ obtido pelo método Kjeldahl. ${ }^{(2)}$ Modelos de regressão: $\mathrm{Q}=$ quadrático; L = linear; ${ }^{*} \mathrm{e}^{* *}$ : significativo a 5 e $1 \%$, respectivamente; ns: não-significativo pelo teste $\mathrm{F}$.

com biossólido com baixos teores de metais pesados, como o avaliado neste trabalho. Por sua vez, Valsecchi et al. (1995) observaram que a aplicação de biossólidos ricos em metais pesados teve efeito adverso sobre a comunidade microbiana de 16 solos, provocando aumento do $q \mathrm{CO}_{2}$ e acúmulo de Corg, pela diminuição da eficiência microbiana na transformação da matéria orgânica e na ciclagem de nutrientes. 
Os quocientes microbianos, Cmic/Corg e Nmic/ Ntotal, bem como as relações Cmic/Nmic e Corg/ Ntotal, não apresentaram diferenças significativas entre os tratamentos (Quadro 2). Os valores médios dos quocientes Cmic/Corg de 2,4 a 3,0 \% são considerados normais por Jenkinson \& Ladd (1981), assim como os de Nmic/Ntotal de 1,6 a 2,2\%, por Smith \& Paul (1990). Como não houve diferença significativa entre as relações $\mathrm{C} / \mathrm{N}$ da área adjacente, considerada como um ambiente em equilíbrio, e os demais tratamentos, observa-se que, mesmo com a aplicação do biossólido e adição dos restos culturais de milho, a imobilização de $\mathrm{C}$ e de $\mathrm{N}$ na biomassa microbiana manteve-se proporcional ao aumento do teor de Corg e $\mathrm{N}$ total do solo, havendo equilíbrio entre as formas de $\mathrm{C}$ e N lábeis e orgânicas no solo, o que é favorável à produção agrícola. É preciso considerar ainda que os lotes de biossólido, quando incorporados ao solo, apresentavam baixas relações $\mathrm{C} / \mathrm{N}$, em torno de 8 , típicas de materiais estabilizados e que não promovem a imobilização de N por microrganismos do solo (Hue, 1995).

A atividade da urease não diferiu entre os tratamentos com biossólido e adubação mineral, e somente com a aplicação da maior dose de biossólido esta foi superior às observadas no controle e na área adjacente. Quanto à atividade específica, esta não diferiu entre tratamentos, indicando que a comunidade produtora de urease manteve-se proporcional na biomassa microbiana em todos os tratamentos, bem como na área adjacente. A atividade da urease apresentou aumento quadrático em resposta às doses de biossólido, atingindo na dose máxima, $555 \mu \mathrm{g} \mathrm{g}^{-1} \mathrm{~h}^{-1} \mathrm{de} \mathrm{N}^{-\mathrm{NH}_{4} \text { no }}$ solo seco, valor quatro vezes superior ao obtido no tratamento controle (Quadro 2). Esse resultado difere dos obtidos por García-Gil et al. (2000), que constataram diminuição de 21 e $28 \%$ na atividade da urease causada pela aplicação de, respectivamente, 20 e 80 t ha $^{-1}$ de lodo urbano compostado, com elevados teores de metais e de $\mathrm{N}-\mathrm{NH}_{4}{ }^{+}$, que são fatores inibitórios da atividade desta enzima.

A atividade da $\beta$-glicosidase obtida com as doses mais elevadas de biossólido foi superior em relação aos tratamentos com adubação mineral e controle, mas não diferiu do valor apresentado na área adjacente, coberta com Brachiaria sp. A elevada atividade da $\beta$-glicosidase nessa condição ocorreu, provavelmente, devido à cobertura vegetal, que, segundo Pascual et al. (2000), fornece substratos carbonados à biota do solo, a partir de exsudatos radiculares e de resíduos vegetais que ativam a população microbiana produtora dessa enzima. Ao contrário do que foi observado para atividade total, a atividade específica da $\beta$-glicosidase atingiu o menor valor com a aplicação de 24 t ha $^{-1}$, refletindo a menor alteração na comunidade de microrganismos produtores dessa enzima na biomassa microbiana do solo nesse tratamento. A atividade da $\beta$-glicosidase foi favorecida e aumentou linearmente em resposta às doses de biossólido, atingindo $895 \mu \mathrm{g} \mathrm{g}^{-1} \mathrm{~h}^{-1}$ de PNG no solo seco com a aplicação da dose máxima. O oposto foi observado na atividade específica, que diminuiu de forma quadrática com o aumento das doses. O aumento linear da $\beta$-glicosidase com a elevação das doses sugere que a fração orgânica do biossólido apresenta grande quantidade de substratos simples, que são degradados por esta enzima, e a diminuição da atividade específica indica que esta é menos dependente de alterações na comunidade microbiana do que enzimas que degradam substratos complexos, como também foi observado por Waldrop et al. (2000). Além disso, a $\beta$-glicosidase libera açúcares simples que, geralmente, são consumidos por bactérias Gram-negativas, de crescimento rápido, e, portanto, incorporados pela microbiota do solo, o que justifica o aumento da biomassa microbiana (Waldrop et al., 2000). GarcíaGil et al. (2000) também verificaram aumento na atividade da $\beta$-glicosidase, sendo este de $100 \%$ em relação ao controle, com a aplicação de $80 \mathrm{t} \mathrm{ha}^{-1}$ de lodo urbano compostado, em razão do estímulo causado pela adição de substratos orgânicos simples contidos naquele resíduo.

As atividades total e específica da fosfatase ácida diminuíram com a aplicação do biossólido, sendo elas superiores no tratamento controle e na área adjacente. Geralmente, a produção dessa enzima é favorecida pela baixa disponibilidade de $\mathrm{P}$ às plantas e aos microrganismos e pode ser inibida por altas concentrações de fosfato inorgânico no solo (Nannipieri et al., 1979). De fato, a aplicação de biossólido e sua suplementação com $36 \mathrm{~kg}_{\text {ha }}{ }^{-1}$ de $\mathrm{P}_{2} \mathrm{O}_{5}$ no segundo ano de aplicação dos tratamentos aumentaram a disponibilidade de $\mathrm{P}$ no solo; mesmo após os dois anos de cultivo do milho, o teor de $5,6 \mathrm{mg} \mathrm{dm}^{-3}$ de $\mathrm{P}$, obtido no tratamento com 24 t ha-1 de biossólido, foi cinco vezes superior ao da área adjacente e oito vezes superior ao do tratamento controle. Esse aumento na disponibilidade de $\mathrm{P}$ no solo, devido à aplicação do biossólido suplementado com $\mathrm{P}_{2} \mathrm{O}_{5}$ mineral, justifica a diminuição das atividades total e específica da fosfatase ácida em resposta às doses crescentes de biossólido. Gagnon et al. (2000) constataram que a aplicação de biossólido gerado por indústria de celulose promoveu aumento da atividade da fosfatase ácida, mas doses superiores a $32 \mathrm{t} \mathrm{ha} \mathrm{a}^{-1}$ reduziram a atividade desta enzima devido ao aumento do teor de $\mathrm{P}$ inorgânico no solo, que foi superior a $100 \mathrm{mg} \mathrm{dm}^{-3}$ de P, extraído por Mehlich-3. García-Gil et al. (2000) também verificaram inibição da atividade da fosfatase ácida em solos tratados com biossólido, devido não só ao aumento de $\mathrm{P}$ solúvel, mas também ao elevado teor de metais pesados presentes no resíduo. Por outro lado, a maior atividade da fosfatase ácida, observada no solo da área adjacente do presente estudo, evidencia a importância desta enzima na mineralização do P-orgânico nas áreas sob vegetação permanente, onde a matéria orgânica é a principal fonte de nutrientes para crescimento das plantas (Pascual et al., 2000). Além disso, é preciso considerar que a atividade da fosfatase reflete tanto a contribuição de microrganismos como de exsudatos radiculares, sendo maior em solos com cobertura vegetal (Dick et al., 1983). 
A hidrólise da FDA apresentou maior atividade nos tratamentos com biossólido que a obtida com adubação mineral e no solo da área adjacente. A atividade específica apresentou comportamento semelhante e foi superior à área adjacente e ao tratamento controle com a aplicação de biossólido em doses superiores a $12 \mathrm{t} \mathrm{ha}^{-1}$. A hidrólise da FDA foi estimulada e aumentou linearmente em resposta às doses de biossólido, variando de 76 a $632 \mu \mathrm{g} \mathrm{g}^{-1} \mathrm{~h}^{-1} \mathrm{de}$ fluoresceína no solo seco com a aplicação da dose máxima, o correspondente a oito vezes o valor obtido no controle, enquanto a atividade específica apresentou aumento quadrático. Como a hidrólise da FDA é usada para quantificar as células ativas nos solos e para caracterizar a atividade microbiana global do solo (Schnürer \& Roswall, 1982), seu aumento em resposta às doses de biossólido indica que este pode estimular a comunidade microbiana do solo, por meio da adição de microrganismos ativos ou pela ativação dos que estão presentes no solo em estado de latência heterotrófica. Chantigny et al. (2000) verificaram valores de FDA próximos a $100 \mu \mathrm{g} \mathrm{g}^{-1} \mathrm{~h}^{-1} \mathrm{de}$ fluoresceína no solo seco após três anos de aplicação de $100 \mathrm{t} \mathrm{ha}^{-1}$ de biossólido. Tardif (1996) relatou atividades na faixa de 50 a $140 \mu \mathrm{g} \mathrm{g}^{-1} \mathrm{~h}^{-1} \mathrm{de}$ fluoresceína no solo seco aplicando 0 a $18 \mathrm{t} \mathrm{ha}^{-1}$ de biossólido de indústria de celulose em solo cultivado com batata. Perucci (1992) reportou valores de 30 a $100 \mu \mathrm{g} \mathrm{g}^{-1} \mathrm{~h}^{-1}$ de fluoresceína no solo seco quando adicionou doses de 0 a $90 \mathrm{t} \mathrm{ha}^{-1}$ de composto de lixo urbano. Nota-se que, nesses trabalhos, a atividade da hidrólise da FDA apresentou valores inferiores aos obtidos com a aplicação de 24 t ha $^{-1}$ do biossólido utilizado no atual estudo.

Apesar da tendência de redução da colonização micorrízica de Brachiaria sp., verificada em plantas de crescimento espontâneo nas parcelas cultivadas, não foram observadas diferenças significativas $(p \geq 0,05)$ entre estas e as da área adjacente (Quadro 2). Os valores de colonização encontrados foram baixos, porém dentro da faixa observada para esta gramínea na região. Siqueira et al. (1989) encontraram valores médios superiores a $30 \%$, embora em algumas amostras a colonização tenha sido de apenas $6 \%$. A densidade de esporos de fungos micorrízicos arbusculares (FMAs) encontrada no solo após o cultivo de milho foi baixa e, em geral, manteve-se inferior à faixa observada para esta cultura, que, de acordo com Siqueira \& Saggin Jr. (1995), pode variar de 10 a 215 esporos $(50 \mathrm{~g})^{-1}$ de solo, dependendo do local avaliado. Nas parcelas cultivadas com milho, o número de esporos foi significativamente inferior ao da área adjacente. Diversos fatores podem ter contribuído para o maior número de esporos na área adjacente. Dentre esses, destaca-se a ausência de cultivo (revolvimento) do solo, que causa o rompimento de hifas e reduz os segmentos de raízes colonizadas que atuam como propágulos no solo (Oehl et al., 2003). A ausência de fertilização na área não-cultivada também pode ter contribuído para sua maior taxa de colonização e esporulação. Os resultados deste trabalho corroboram os de Oehl et al. (2003), que também observaram maior densidade de esporos de FMAs em solo sob pastagens contínuas que em áreas com manejo intensivo do solo e cultivadas com milho em monocultura.

Embora tenha sido encontrado baixo número de esporos de FMAs em solo tratado com biossólido e adubação mineral, esses tratamentos não diferiram significativamente entre si, não caracterizando, portanto, a existência de efeito adverso da aplicação do biossólido sobre os FMAs. Provavelmente, o aumento da disponibilidade de $\mathrm{P}$ no solo nesses tratamentos tenha contribuído também para a baixa micorrização. Apesar da menor densidade de esporos no solo após a aplicação de biossólido e cultivo de milho, foi detectado maior número de espécies de FMAs no solo com estes tratamentos em relação ao da área adjacente. Enquanto nesta área foram encontrados somente esporos de Paraglomus occultum (Walker) Morton \& Redecker e Scutellospora heterogama (Nicolson \& Gerdemann) Walker \& Sanders, na área cultivada com milho também foram encontrados esporos de várias espécies: Acaulospora spinosa (Walker \& Trappe), Acaulospora scrobiculata (Trappe), Archaeospora leptoticha (Spain, Sieverding \& Schenck), Scutellospora pellucida (Nicolson \& Schenck) Walker \& Sanders, Scutellospora sp. e Gigaspora sp. Destas, apenas A. scrobiculata e A. spinosa foram encontradas nesta cultura por Siqueira et al. (1989). Bever (2002) também observou enriquecimento de espécies de FMAs em solos repetidamente cultivados com milho nos Estados Unidos. Miranda et al. (2005) também constataram aumento do número de gêneros e espécies de FMAs com o aumento do tempo de cultivo do solo e do manejo de culturas, sendo estes maiores sob culturas anuais em rotação no cerrado.

A matriz de correlações mostra a existência de várias relações significativas entre as características biológicas avaliadas (Quadro 3). A biomassa microbiana apresentou correlações positivas com o teor de Corg do solo e com a atividade medida pela respiração e pela maioria das enzimas extracelulares, evidenciando que o aumento da respiração se deveu ao aumento da biomassa e não ao aumento do consumo de energia. A correlação inversa do $q \mathrm{CO}_{2}$ com o aumento do Cmic, Nmic e atividade microbiana indica que a microbiota permaneceu ativa na biodegradação dos compostos orgânicos e eficiente na utilização desses substratos para obtenção de energia. A alta correlação da atividade hidrolítica da FDA com Cmic, Nmic e respiração indica que esta enzima pode ser empregada como referência para a atividade microbiana global do solo, como sugerido por Diack (1997). A $\beta$-glicosidase apresentou alta correlação com Corg e Cmic por estar diretamente envolvida com a mineralização de compostos carbonados do biossólido, o que também foi observado por García-Gil et al. (2000). O aumento da atividade hidrolítica da FDA, da $\beta$-glicosidase e 
Quadro 3. Coeficientes de correlação de Pearson entre características biológicas do solo após dois anos consecutivos da aplicação de doses crescentes de biossólido industrial e de adubação mineral no cultivo de milho e do solo da área adjacente, coberta com Brachiaria sp. $^{(1)}$

\begin{tabular}{|c|c|c|c|c|c|c|c|c|c|c|c|c|c|c|}
\hline Característica & Cmic & Nmic & RESP & $q \mathrm{CO}_{2}$ & $\beta-\mathbf{G l}$ & URE & FOSF & FDA & Corg & $\begin{array}{c}\mathrm{N} \\
\text { total }\end{array}$ & $\begin{array}{c}\text { Corg /N } \\
\text { total }\end{array}$ & $\begin{array}{l}\text { Cmic/ } \\
\text { Nmic }\end{array}$ & $\begin{array}{l}\text { Nmic/ } \\
\text { Ntotal }\end{array}$ & $\begin{array}{l}\text { Cmic/ } \\
\text { Corg }\end{array}$ \\
\hline Cmic & - & & & & & & & & & & & & & \\
\hline Nmic & $0,95^{* *}$ & - & & & & & & & & & & & & \\
\hline RESP & $0,98^{* *}$ & $0,92^{* *}$ & - & & & & & & & & & & & \\
\hline$q \mathrm{CO}_{2}$ & $-0,90^{* *}$ & $-0,88^{* *}$ & $-0,84^{* *}$ & - & & & & & & & & & & \\
\hline$\beta$-GI & $0,62^{*}$ & $0,75^{*}$ & $\mathrm{~ns}$ & $\mathrm{~ns}$ & - & & & & & & & & & \\
\hline URE & $0,75^{*}$ & $0,84^{* *}$ & $0,83^{* *}$ & $\mathrm{~ns}$ & $\mathrm{~ns}$ & - & & & & & & & & \\
\hline FOSF & $-0,95^{* *}$ & $-0,86^{* *}$ & $-0,96^{* *}$ & $0,79 * *$ & ns & $-0,73^{*}$ & - & & & & & & & \\
\hline FDA & $0,99 * *$ & $0,97^{* *}$ & $0,97^{* *}$ & $-0,89^{* *}$ & $0,66^{*}$ & $0,76^{*}$ & $-0,95^{* *}$ & - & & & & & & \\
\hline Corg & $0,99 * *$ & $0,97 * *$ & $0,95^{* *}$ & $-0,88^{* *}$ & $0,71^{*}$ & $0,73^{*}$ & $-0,90^{* *}$ & $0,99 * *$ & - & & & & & \\
\hline Ntotal & $0,99^{* *}$ & $0,95^{* *}$ & $0,97^{* *}$ & $-0,93^{* *}$ & $\mathrm{~ns}$ & $0,74^{*}$ & $-0,95^{* *}$ & $0,99^{* *}$ & $0,97^{* *}$ & - & & & & \\
\hline Corg / $\mathrm{N}$ total & ns & $0,76^{*}$ & $\mathrm{~ns}$ & $\mathrm{~ns}$ & $0,80^{* *}$ & * $\mathrm{ns}$ & $\mathrm{ns}$ & $0,65^{*}$ & $0,71^{*}$ & $\mathrm{~ns}$ & - & & & \\
\hline $\mathrm{Cmic} / \mathrm{Nmic}$ & $0,86^{* *}$ & $0,67^{*}$ & $0,85^{* *}$ & $-0,79^{*}$ & $\mathrm{~ns}$ & $\mathrm{~ns}$ & $-0,89^{* *}$ & $0,82^{* *}$ & $0,79^{* *}$ & $0,86^{* *}$ & ns & - & & \\
\hline $\mathrm{Nmic} / \mathrm{N}$ total & $\mathrm{ns}$ & $\mathrm{ns}$ & $\mathrm{ns}$ & $\mathrm{ns}$ & $\mathrm{ns}$ & $\mathrm{ns}$ & $0,64^{*}$ & ns & ns & ns & ns & $-0,81 * *$ & - & \\
\hline Cmic/Corg & $0,70^{*}$ & $\mathrm{~ns}$ & $0,74^{*}$ & $-0,70^{*}$ & $\mathrm{~ns}$ & $\mathrm{~ns}$ & $-0,77^{*}$ & $\mathrm{~ns}$ & $\mathrm{~ns}$ & $0,71^{*}$ & $\mathrm{~ns}$ & $0,85^{* *}$ & $0,75^{*}$ & - \\
\hline
\end{tabular}

(1) Cmic e Nmic: carbono e nitrogênio da biomassa microbiana; RESP: respiração basal; $q C O_{2}$ : quociente metabólico; $\beta$-Gl: $\beta$ glicosidase; URE: urease; FOSF: fosfatase ácida; FDA: hidrólise do diacetato de fluoresceína; Corg: carbono orgânico; Ntotal: N obtido pelo método Kjeldahl. ${ }^{*} \mathrm{e}^{* *}$ : correlações significativas a 5 e $1 \%$, respectivamente; ns: não-significativo pelo teste t.

da urease correlacionou-se positivamente com o Corg do solo e inversamente com a atividade da fosfatase. Kumari \& Singaram (1995) observaram que a maior produção de biomassa e da atividade enzimática correlacionou-se com a melhoria da fertilidade do solo. De fato, houve correlação positiva entre o teor de Ntotal e o de Corg do solo com o aumento da biomassa e da atividade microbiana avaliada pela respiração e pela produção de enzimas extracelulares. Segundo Frankenberger \& Dick (1983), essa relação entre fertilidade e atividade microbiana resulta dos efeitos da maior decomposição dos resíduos orgânicos sobre a abundância e atividade dos microrganismos do solo. Portanto, as correlações positivas entre características biológicas e de fertilidade do solo sugerem que o uso agrícola desse biossólido favoreceu o crescimento da biomassa e estimulou a atividade microbiana, que se mostrou eficiente nos processos de ciclagem de nutrientes e melhorou a qualidade do solo.

A correlação negativa da atividade da fosfatase ácida com a maioria dos parâmetros biológicos (Quadro 3) indica que o biossólido, embora tenha estimulado o crescimento e o metabolismo microbiano, inibiu a população produtora de fosfatase, provavelmente pelo aumento da disponibilidade de $\mathrm{P}$, como já comentado. A correlação inversa entre atividade da fosfatase e disponibilidade de $\mathrm{P}$, em solo tratado com biossólido, também foi observada por García-Gil et al.
(2000). A inibição da fosfatase, nesse caso, não caracteriza efeito adverso do uso agrícola do biossólido, considerando que existe equilíbrio entre a atividade enzimática e a disponibilidade de $\mathrm{P}$ no solo e que essa enzima é produzida somente quando os teores de $\mathrm{P}$ solúvel atingem níveis limitantes ao crescimento de plantas e microrganismos do solo (Fernandes et al., 1998).

A elevada correlação do conteúdo de Corg e da biomassa microbiana com as demais características avaliadas (Quadro 3) reforça o conceito de que as alterações na quantidade e qualidade do Corg do solo, promovidas pela aplicação do biossólido, tiveram reflexos sobre a dinâmica da biomassa microbiana e influenciaram os processos bioquímicos.

Os resultados dessa avaliação indicam que o biossólido não apresentou efeito adverso e estimulou o crescimento e a atividade microbiana, favorecendo a produção de enzimas extracelulares responsáveis pela transformação de compostos orgânicos na ciclagem de nutrientes e que estão diretamente relacionadas à melhoria da fertilidade do solo. De fato, a aplicação desse biossólido por dois anos consecutivos melhorou a fertilidade do solo, o estado nutricional e a produtividade do milho e, mesmo na maior dose, não causou toxicidade à cultura (Trannin et al., 2005). Com base nesses aspectos, este biossólido apresenta 
potencial de uso como condicionador da qualidade do solo, devido ao seu elevado conteúdo de matéria orgânica e de nutrientes e ao baixo teor de metais pesados, características estas que estimulam a ativação de processos bioquímicos, que melhoram a fertilidade do solo e, conseqüentemente, favorecem a produtividade das culturas.

\section{CONCLUSÕES}

1. Mesmo após os dois anos consecutivos da aplicação de doses crescentes do biossólido no cultivo de milho, foram constatadas alterações na matéria orgânica do solo e melhoria na maioria das características biológicas relacionadas à fertilidade do solo.

2. A aplicação do biossólido favoreceu de forma consistente as características estudadas, aumentando as concentrações de $\mathrm{C}$ e $\mathrm{N}$ na biomassa microbiana $\mathrm{e}$ os processos bioquímicos indicadores de qualidade do solo.

3. A colonização micorrízica de Brachiaria sp. e a esporulação não foram favorecidas pela aplicação do biossólido, porém houve enriquecimento de espécies de fungos micorrízicos arbusculares na área cultivada.

4. A aplicação desse biossólido nas doses estudadas não exerceu efeito adverso sobre os principais parâmetros biológicos do solo.

5. Os resultados favoráveis da aplicação do biossólido sobre características biológicas indicadoras de qualidade do solo se devem ao elevado teor de matéria orgânica e de nutrientes e ao baixo teor de metais pesados desse resíduo.

\section{LITERATURA CITADA}

ALEF, K. \& NANNIPIERI, P. Methods in applied soil microbiology and biochemistry. London, Academic Press, 1995. $576 \mathrm{p}$

ANDERSON, T.H. \& DOMSCH, K.H. The metabolic quocient for $\mathrm{CO}_{2}\left(q \mathrm{CO}_{2}\right)$ as a specific activity parameter to assess the effects of environmental conditions, such as $\mathrm{pH}$, on the microbial biomass of forest soils. Soil Biol. Biochem., 25:393-395, 1993.

BANERJEE, M.R.; BURTON, D.L. \& DEPOE, S. Impact of sewage sludge application on soil biological characteristics. Agric. Ecosyst. Environ., 66:241-249, 1997.
BETTIOL, W. \& CAMARGO, O.A. Impacto ambiental do uso agrícola do lodo de esgoto. Jaguariúna, Embrapa Meio Ambiente, 2000. 312p.

BEVER, J.D. Host-specificity of AM fungal populations growth rates can generate feedback on plant growth. Plant Soil, 244:281-290, 2002.

BROOKES, P.C. The use of microbial parameters in monitoring soil pollution by heavy metals. Biol. Fert. Soils, 19:269-279, 1995.

BROOKES, P.C.; LANDMAN, A.; PRUDEN, G. \& JENKINSON, D.S. Cloroform fumigation and the release of soil nitrogen: A rapid direct extraction method to measure microbial biomass nitrogen in soil. Soil Biol. Biochem., 17:837-842, 1985.

CHANTIGNY, M.H.; ANGERS, D.A. \& BEAUCHAMP, C.J. Active carbon pools and enzyme activities in soils amended with de-inking paper sludge. Can. J. Soil Sci., 80:99-105, 2000.

COMPANHIA DE TECNOLOGIA DE SANEAMENTO AMBIENTAL - CETESB. Aplicação de biossólidos de sistemas de tratamento biológico em áreas agrícolas: Critérios para projeto e operação. São Paulo, 1999. 29p. (CETESB, Norma P. 4. 230)

DEBOSZ, K.; PETERSEN, S.O.; KURE, L.K. \& AMBUS, P. Evaluating effects of sewage sludge and household compost on soil physical, chemical and microbiological properties. Appl. Soil Ecol., 19:237-248, 2002.

DIACK, M. Relationships between soil biological and chemical characteristics and surface soil structural properties for use in soil quality. West Lafayette, Purdue University, 1997. 221p. (Tese de Doutorado)

DICK, R.P.; BREAKWELL, D.P. \& TURCO, R.F. Soil enzyme activities and biodiversity measurements as integrative microbiological indicators. In: DORAN, J.W. \& JONES, A.J. Methods for assessing soil quality. Madison, Soil Science Society of America, 1996. p.247-272.

DICK, W.A.; JUMA, N.G. \& TABATABAI, M.A. Effects of soils on acid phosphatase and inorganic pyrophosphatase of corn roots. Soil Sci., 136:19-25, 1983.

EATON, A.D.; CLESCERI, L.S. \& GRENNBERG, A.E., eds. Standard methods for the examination of water and wastewater. 19.ed. Washington, APHA, AWWA, WEF, 1995. 1082p.

EIVAZI, F. \& TABATABAI, M.A. Glucosidases and galactosidases in soils. Soil Biol. Biochem., 20:601-606, 1988.

FEIGL, B.J.; SPARLING, G.P.; ROSS, D.J. \& CERRI, C.C. Soil microbial biomass in Amazonian soils: Evaluation of methods and estimates of pool sizes. Soil Biol. Biochem., 27:1467-1472, 1995. 
FERNANDES, L.A.; FURTINI NETO, A.E.; CURI, N.; LIMA, J.M. \& GUEDES, G.A.A. Fósforo e atividade de fosfatase em dois solos sob diferentes condições de uso. Pesq. Agropec. Bras., 33:1159-1170, 1998.

FERREIRA, D.F. SISVAR - programa estatístico. Versão 4.2 (Build 39). Lavras, Universidade Federal de Lavras, 19992003.

FRANKENBERGER, W.T. \& DICK, W.A. Relationships between enzyme activities and growth and activity indices in soil. Soil Sci. Soc. Am. J., 47:945-951, 1983.

GAGNON. B.; LALANDE, R.; SIMARD, R.R. \& ROY, M. Soil enzyme activities following paper sludge addition in a winter cabbage-sweet corn rotation. Can. J. Soil Sci., 80:91-97, 2000.

GAMA-RODRIGUES, E.F. \& DE-POLLI, H. Biomassa na ciclagem de nutrientes. In: FERTIBIO 2000. Santa Maria, 2000. Anais. Santa Maria, Sociedade Brasileira de Ciência do Solo, 2000. CD-ROM

GARCÍA-GIL, J.C.; PLAZA, C.; SOLER-ROVIRA, P. \& POLO, A. Long-term effects of municipal solid waste compost application on soil enzyme activities and microbial biomass. Soil Biol. Biochem., 32:1907-1913, 2000.

GERDEMANN, J.W. \& NICOLSON, T.H. Spores of mycorrhizal endogamous species extracted from soil by wet sieving and decanting. British Mycol. Soc. Trans., 46:235-244, 1963.

GIOVANNETTI, M. \& MOSSE, B. An evaluation of techniques for measuring vesicular arbuscular mycorrhizal infection in roots. New Phytol., 84:489-500, 1980.

HUE, N.V. Sewage sludge. In: RECHEIGL, J.E., ed. Soil amendments and environmental quality. Boca Raton, Lewis Publishers, 1995. p.199-247.

JENKINSON, D.S. \& LADD, J.M. Microbial biomass in soil: Movement and turnover. In: PAUL, E.A. \& LADD, J.M., eds. Soil biochemistry. New York, Marcel Dekker, 1981. p.368-386.

KOOMEN, I.; McGRATH, S.P. \& GILLER, K.E. Mycorrhizal infection of clover is delayed in soils contaminated with heavy metals from past sewage sludge applications. Soil Biol. Biochem., 22:871-873, 1990.

KUMARI, K.K. \& SINGARAM, P. Relationship among soil chemical, biochemical properties and enzyme activities. Madras Agric. J., 82:69-70, 1995.

MIRANDA, J.C.C.; VILELA, L. \& MIRANDA, L.N. Dinâmica e contribuição da micorriza arbuscular em sistemas de produção com rotação de culturas. Pesq. Agropec. Bras., 40:1005-1014, 2005

NANNIPIERI, P.; PECHOZZINI, F.; ARCADA, P.G. \& PIORANELLI, C. Changes in amino acids, enzyme activities and biomass during soil microbial growth. Soil Sci., 127:24-36, 1979.
OEHL, F.; SIEVERDING, E.; INEICHEN, K.; MADER, P.; BOLLER, T. \& WIEMKEN, A. Impact of land use intensity on the species diversity of arbuscular mycorrhizal fungi in agroecosystems of Central Europe. Appl. Environ. Microbiol., 69:2816-2824, 2003.

PASCUAL, J.A.; GARCIA, C.; HERNANDEZ, T.; MORENO, J.L. \& DA ROS, M. Soil microbial activity as a biomarker of degradation and remediation processes. Soil Biol. Biochem., 32:1977-1883, 2000.

PERUCCI, P. Enzyme activity and microbial biomass in a field soil amended with municipal refuse. Biol. Fert. Soils, 14:5460, 1992 .

PHILLIPS, J.M. \& HAYMAN, D.S. Improved procedures for clearing roots and staining parasitic and vesiculararbuscular mycorrhizal fungi for rapid assessment of infection. British Mycol. Soc. Trans., 55:158160,1970

SIQUEIRA, J.O. \& SAGGIN Jr., O.J. The importance of mycorrhizae association in natural low fertility soils. In: MACHADO, A.T.; MAGNAVACA, R.; PANDEY, S. \& SILVA, A.F., eds. INTERNATIONAL SYMPOSIUM ON ENVIRONMENTAL STRESS: MAIZE IN PERSPECTIVE, Brasília, 1992. Anais. Brasília, Embrapa, 1995. p.240-280.

SCHNÜRER, J. \& ROSSWALL, T. Fluorescein diacetate hydrolysis as a measure of total microbial activity in soil and litter. Appl. Environ. Microbiol., 43:1256-1261, 1982.

SILVA NETO, J.P. Efeito da inoculação de fungos micorrízicos em mudas de maracujazeiro amarelo (Passiflora edulis Sims f. flavicarpa Deg) em substrato com biossólido. Recife, Universidade Federal Rural de Pernambuco, 2001. 105p. (Tese de Mestrado)

SIQUEIRA, J.O.; COLOZZI FILHO, A. \& OLIVEIRA, E. Ocorrência de micorriza vesículo-arbuscular em agroecossistemas do Estado de Minas Gerais. Pesq. Agropec. Bras., 24:1499-1506, 1989.

SMITH, J.L. \& PAUL, E.A. The significance of soil microbial biomass estimations. In: BOLLAG, J.M. \& STOTZKY, G., eds. Soil biochemistry. New York, Marcel Dekker, 1990. p.357-396

SPARLING, G.P. Ratio of biomass carbon to soil organic carbon as a sensitive indicator of changes in soil organic matter. Aust. J. Soil Res., 30:195-207, 1992.

TABATABAI, M.A. \& BREMNER, J.M. Assay of urease activity in soil. Soil Biol. Biochem., 4:479-487, 1972.

TARDIF, J. Impact des résidus de désencrage sur la microflore d'un sol en culture de pomme de terre. Québec, Université Laval, 1996. (Tese de Mestrado)

TRANNIN, I.C.B.; SIQUEIRA, J.O. \& MOREIRA, F.M.S. Avaliação agronômica de um biossólido industrial para a cultura do milho. Pesq. Agropec. Bras., 40:261-269, 2005. 
VALSECCHI, G.; GIGLIOTTI, C. \& FARINI, A. Microbial biomass, activity and organic matter accumulation in soils contaminated with heavy metals. Biol. Fert. Soils, 20:253259, 1995 .

VANCE, E.D.; BROOKES, P.C. \& JENKINSON, D.S. An extraction method for measuring microbial biomass C. Soil Biol. Biochem., 19:703-707, 1987.
WALDROP, M.P.; BALSER, T.C. \& FIRESTONE, M.K. Linking microbial community composition to function in a tropical soil. Soil Biol. Biochem., 32:1837-1846, 2000.

WEISSENHORN, I.; MENCH, M. \& LEYVAL, C. Bioavailability of heavy metals and arbuscular mycorrhiza in a sewage-sludge-amended sandy soil. Soil Biol. Biochem., 27:287-296, 1995. 